\title{
Avaliação energética e de desempenho de frangos com aquecimento automático a gás e a lenha
}

\author{
Sandro R. Funck ${ }^{1} \&$ Ricardo A. Fonseca ${ }^{2}$
}

\begin{abstract}
RESUMO
Nesta pesquisa foram analisados aquecimento automático infravermelho a gás e aquecimento automático a lenha, com três linhagens de frango, criados no período de 01/05/2005 a 16/06/2005, em aviários de $1200 \mathrm{~m}^{2}$ e abatidos com 45 dias de idade. Avaliaram-se o consumo e o custo energético de cada sistema e os seguintes índices zootécnicos: peso médio, mortalidade, conversão alimentar e consumo de ração. O delineamento experimental foi inteiramente casualizado em um modelo fatorial $2 \times 3$, constituído de dois sistemas de aquecimento e das três linhagens de frangos machos formando seis tratamentos com seis repetições, perfazendo o total de trinta e seis aviários com 13.300 aves cada um. Utilizou-se, para a análise estatística, o programa SISVAR 4.6 e se realizaram as comparações entre as médias através do teste de Tukey. Os resultados obtidos foram os seguintes: o consumo energético de lenha de 173,21 GJ por lote e o custo de $R \$ 3,23$ e, para o do gás, foi de 20,26 GJ por lote e o custo de $R \$ 53,76$. Em relação ao desempenho zootécnico, não houve diferença significativa entre os dois sistemas analisados, mas entre as linhagens ocorreu diferença significativa, com a linhagem Cobb apresentando 6,62\%, maior peso médio e 1,04\% maior mortalidade, quando comparada com aves da linhagem Ross 1.
\end{abstract}

Palavras-chave: consumo energético, custo de energia, índices zootécnicos, ambiência, aves

\section{Energetic evaluation and performance of broilers with automatic heating using gas and wood}

\begin{abstract}
In this research automatic infra-red gas heating and wood-burning were analyzed, with three lineages of broilers raised from May 1, 2005 to June 16, 2005 in $1200 \mathrm{~m}^{2}$ poultry houses, and slaughtered at the age of 45 days. The energetic consumptions and costs were evaluated for each system, as well as the following zootechnical indexes: mean weight, mortality, feed conversion and consumption. The experimental design was completely randomized in a factorial $2 \times 3$ model, made up by two heating systems, three lineages of male broilers and six treatments and six replications, totaling thirty six poultry houses with 13,300 birds each. For the statistical analysis the SISVAR 4.6 program was utilized and the comparisons of means were done using the Tukey test. The results obtained were as follows: the energy consumption for wood was $173.21 \mathrm{G}$ ) per lot and the cost was $\mathrm{R} \$ 3.23 \mathrm{G}$ j per lot, and for gas it was $20.26 \mathrm{G}$ ) per lot with a cost $\mathrm{R} \$ 53.78 \mathrm{G}$ ) per lot. In relation to the zootechnical performance, there were no significant differences between the two systems, but for the lineages significant difference was observed. The Cobb lineage had a $6.62 \%$ higher mean weight and $1.04 \%$ higher mortality when compared to the Ross 1 lineage.
\end{abstract}

Key words: energy consumption, energy cost, zootechnical indexes, environment, birds

MESAGRI/UNIOESTE. CEP 85.807-140, Cascavel, PR. Fone: (45) 3226-2304. E-mail: sandrorfunck@ibest.com.br

2 DECBIO/FAFIPAR/UNESPAR e MESAGRI/UNIOESTE. Rua Comendador Corrêa Júnior, 117, CEP 83.203-280, Paranaguá, PR. Fone: (41) 3423-3644.

E-mail: ricardoalvesdafonseca@yahoo.com.br 


\section{INTRODUÇÃO}

O melhoramento genético fez com que o frango de corte ganhasse 2,5 $\mathrm{g} \mathrm{h}^{-1}$ de vida mas, para que isto ocorresse, foi conveniente oferecer boa nutrição, bom estado sanitário e condições adequadas de ambiente, dentro do aviário. Esses fatores constituem uma preocupação constante dos técnicos das empresas avícolas.

Devido às características do metabolismo intenso da ave, de toda energia consumida pelo frango somente $20 \%$ são carreados para o seu crescimento e os outros $80 \%$ se destinam à sua manutenção (Abreu \& Abreu, 2004).

Observa-se que, apesar de se haver conquistado altos índices de produção, a instalação avícola é um dos pontos em que se exigem, atualmente, maiores preocupações, em se tratando do conforto térmico para frango de corte (Abreu \& Abreu, 2001).

Como as aves são animais homeotermos e possuem um centro termorregulador no sistema nervoso central, o hipotálamo, que é um órgão que funciona como termostato fisiológico, controlando a produção e dissipação de calor através de diversos mecanismos, como o fluxo sanguíneo na pele, mudança na freqüência cardíaca e respiratória e modificação na taxa metabólica (Moro, 1995). O aparelho termorregulador das aves é pouco desenvolvido, tornando-as sensíveis ao frio quando jovens e ao calor quando adultas.

A capacidade de termorregulação da ave ao frio é maior que a capacidade para reagir ao calor, tanto que o limite inferior da zona de conforto da ave está em torno de $12{ }^{\circ} \mathrm{C}$, ou seja, $30^{\circ} \mathrm{C}$ abaixo de sua temperatura corporal e a temperatura limite superior é de $47^{\circ} \mathrm{C}$, apenas $5^{\circ} \mathrm{C}$ acima de sua temperatura interna é letal para ela (Baião, 1995).

Pesquisas demonstram que a temperatura corporal de um pintinho de um dia é, em média, $1,7^{\circ} \mathrm{C}$ menor que a temperatura corporal das aves adultas, mas com cinco dias de vida, atingem temperaturas corporais de $41,1^{\circ} \mathrm{C}$ (Veste, 1997).

Para manter a temperatura relativamente constante para os órgãos vitais, o calor corporal deve ser conservado ou liberado, como resposta às mudanças do meio ambiente.

A maior taxa de formação de órgãos vitais, como coração, pulmão, sistema digestivo e imunológico, ocorre durante os primeiros 7 dias de vida dos pintos; para que este desenvolvimento seja normal, os pintos necessitam absorver todos os nutrientes e anticorpos contidos no saco embrionário; isto só ocorrerá se eles forem mantidos a uma temperatura em torno de $32{ }^{\circ} \mathrm{C}$ e ingerirem água e ração, pois se a temperatura for muito baixa eles permanecerão agrupados e encolhidos e não irão até os comedouros e bebedouros. Se os pintos sofrerem com o frio, o seu desenvolvimento será prejudicado, dar-se-á redução na taxa de ganho de peso e piora na conversão alimentar. Essas perdas normalmente não serão completamente recuperadas até o abate do lote de frangos (Conto, 2003).

Estudos demonstram que, em se expondo um pinto de um dia a curtos períodos de baixas temperaturas, pode ocorrer efeito negativo a longo prazo no desempenho da ave, no seu crescimento, conversão alimentar, aumentando a sua susceptibilidade às doenças (Czarick \& Lacy, 1996).
Veste (1997) recomendou, para aves jovens na primeira semana de vida, temperaturas de $32,2{ }^{\circ} \mathrm{C}$, para aviários com ambiente não controlado e temperaturas de 29,4 a $31{ }^{\circ} \mathrm{C}$ para aviários com ambiente totalmente controlado; desta forma, mantendo a temperatura de aquecimento nos níveis desejáveis e se atentando para as outras práticas de manejo, consegue-se manter o crescimento das aves em níveis adequados e a uniformidade do lote, além de melhorar a conversão alimentar.

É importante observar a temperatura da cama e não somente a temperatura do ar; recomenda-se, então, uma temperatura de cama de aproximadamente $29,4{ }^{\circ} \mathrm{C}$ para a primeira semana de vida das aves (Czarick \& Lacy, 1996).

Para determinada faixa de temperatura efetiva, Abreu et al. (1998) relataram que a ave mantém constante a temperatura corporal com o mínimo esforço dos mecanismos temorreguladores; é a chamada zona de conforto térmico, em que não há sensação de frio ou de calor e o desempenho do animal é otimizado.

Na zona de conforto térmico a taxa metabólica é mínima e a homeotermia é mantida com menos gasto energético; assim, na zona de termoneutralidade a fração de energia metabolizável utilizada para a termogênese é mínima e a energia líquida de produção é máxima (Mount, 1979, apud Macari et al., 1994).

Um dos principais fatores que afetam a zona de conforto térmico é a idade do animal. Com o desenvolvimento do frango de corte a conseqüente maturação do sistema termorregulador e o aumento da atividade energética, a zona de conforto térmico é reduzida de $35^{\circ} \mathrm{C}$, com um dia de idade, para $24^{\circ} \mathrm{C}$, com quatro semanas de idade e para 21 a $22^{\circ} \mathrm{C}$, com seis semanas de idade (Macari et al., 1994).

O melhor indicativo da temperatura, segundo Marques (1994), é o próprio comportamento do pinto; é ele que estabelece, por seu comportamento, a adequação das condições térmicas do sistema de aquecimento. Pode haver locais sob a campânula em que a radiação é muito mais forte e os pintos se afastam, deixando espaços vazios; se existe muita aglomeração, trata-se de indício da necessidade de mais aquecimento; assim, a variação da temperatura da pele durante o estresse calórico, evidencia um aumento do fluxo sangüíneo para a superfície da ave para dissipação de calor, o qual é refletido pela maior temperatura da pele; contudo, quando a temperatura no interior do aviário está abaixo da ideal para os pintos, ocorre a piloereção, redução no fluxo sangüíneo cutâneo e aumenta a camada de ar que proporciona um isolamento maior da superfície da pele e eleva a produção metabólica de calor por termogênese, mediante tremores e não tremores. Neste sentido, e com o objetivo de reduzir a perda de calor, aves submetidas a baixas temperaturas ambientes sofrem alterações hemodinâmicas e vasoconstrição periférica, resultando em um baixo gradiente de temperatura entre a pele e o ambiente, reduzindo as perdas por convecção e irradiação (Muller, 1989; Yahav et al., 1998; Silva, 2000).

$\mathrm{Na}$ tentativa de resolver essas questões de ambiência, os aviários estão, atualmente, aparelhados com equipamentos de climatização, tais como: exaustores, nebulizadores, sistemas de aquecimento a lenha ou infravermelho a gás, painéis 
de controle, nos quais são programadas a temperatura e a umidade do ar para cada idade dos frangos, além de cortinado, forração.

Para fornecer calor e proporcionar conforto térmico às aves, no período inicial de criação, vários tipos de aquecedores têm sido utilizados; a evolução desses equipamentos se deu sempre na busca de uma forma melhor de transferir o calor com menor custo de energia (Moro, 1995).

Conto (2003) acrescenta que eficiência de transformação da energia contida no combustível em energia térmica e as perdas envolvidas nos processos de transmissão de calor, devem ser preponderantes na determinação de um ou outro sistema de fornecimento de calor. Experimentos demonstram que pintinhos de corte necessitam receber calor suplementar, na ordem de 3 a $4 \mathrm{kcal} \mathrm{h}^{-1}$, para cada ave.

Segundo Abreu \& Abreu (2002), existem, basicamente, dois grupos de aquecimento para manter a temperatura ambiente dentro da região de conforto térmico das aves, o aquecimento central e o local. O aquecimento central se baseia no aquecimento relativamente homogêneo de todo o volume dos aviários, enquanto o local se baseia no aquecimento apenas da superfície do local em que se alojam os pintos, sendo um processo bastante eficiente, em termos de economia de energia.

Abreu et al. (1998) citam que o aumento do preço do gás fez com que as indústrias procurassem novas alternativas para fornecer calor às aves, propondo um sistema de aquecimento automático a lenha, que consiste em soprar ar quente para dentro do aviário através de uma turbina e distribuído por um sistema de tubulações, colocado ao longo do aviário; este sistema diminui os gases tóxicos dentro do aviário, com melhor controle de temperatura; o sistema trabalha com energia renovável, podendo o produtor gerar o próprio combustível bastando, para isto, possuir um programa de reflorestamento.

Objetivou-se, com o presente trabalho, avaliar o sistema de aquecimento automático infravermelho a gás e o sistema de aquecimento automático a lenha, em relação ao desempenho zootécnico de frangos de corte quanto à conversão alimentar, mortalidade, peso das aves e consumo de ração, e determinar o consumo específico de energia de cada sistema de aquecimento e o seu custo, em uma agroindústria avícola, nas linhagens Ross 1, Ross 2 e Cobb.

\section{MATERIAL E MÉTODOS}

O experimento foi realizado em aviários da região oeste do Paraná, nos municípios de Cascavel, cujas coordenadas geográficas são: $24^{\circ} 58^{\prime}$ 00” Sul e 53²6’ 00” Oeste, de Toledo, localizado geograficamente pela coordenadas $24^{\circ} 45^{\prime} 00^{\prime \prime}$ Sul e $53^{\circ} 41^{\prime} 00^{\prime}$ ' Oeste e de Guaraniaçu, em que as coordenadas geográficas são: $25^{\circ} 08$ ' 00” Sul e 52 $20^{\circ}$ 00” Oeste.

Os aviários experimentais, em número de 36, têm as dimensões de: $12 \mathrm{~m}$ de largura por $100 \mathrm{~m}$ de comprimento e 2,7 m de altura, cobertos com telhas de barro, muretas laterais com $40 \mathrm{~cm}$ de altura, tela metálica, com forração e cortinas laterais, nos quais foram alojadas 478.800 aves, sendo em cada aviário 13.300 frangos machos das linhagens Ross 1,
Ross 2 e Cobb, disponíveis no mercado brasileiro, abatidos com idade média de 45 dias e peso médio de $2,683 \mathrm{~kg}$. As propriedades são integradas junto a uma agroindústria avícola localizada na região; o período da coleta dos dados foi de 1 de maio de 2005 a 16 de junho de 2005, em que se comparou o sistema de aquecimento automático a lenha e o sistema de aquecimento automático infravermelho a gás.

O sistema de aquecimento automático a lenha (Figura 1) é constituído de uma fornalha com capacidade de 0,9 $\mathrm{m}^{3}$ e autonomia de 5 h, com uma câmara de ar, uma turbina, um motor elétrico de $2 \mathrm{cv}$, uma chaminé ao redor da qual existe uma tubulação para puxar o ar que foi aquecido, tubulações para distribuir o ar aquecido no interior do aviário, um sensor e um painel de controle. O ar é aquecido por condução e no sistema de aquecimento automático a gás, o ar é aquecido por radiação.

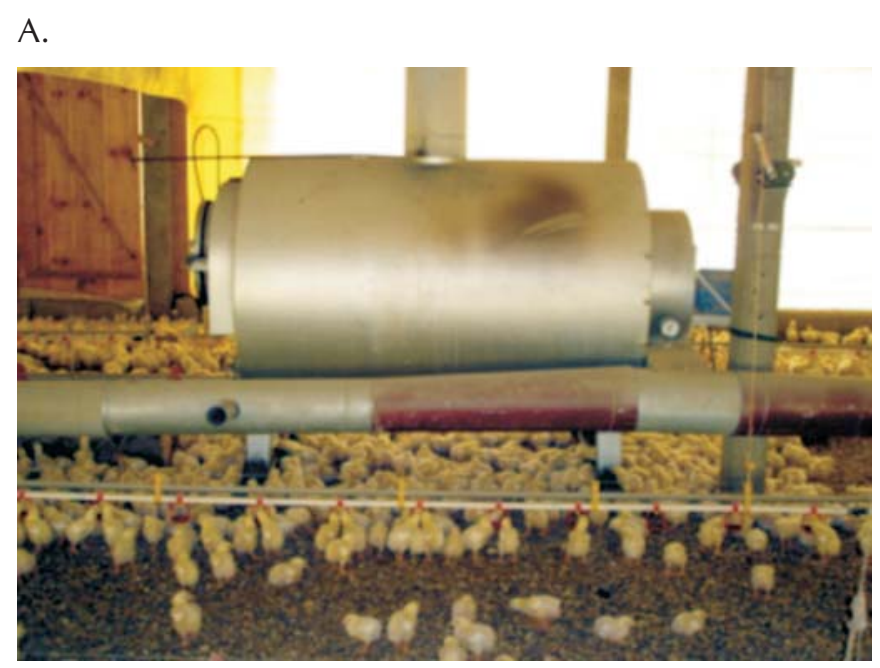

B.

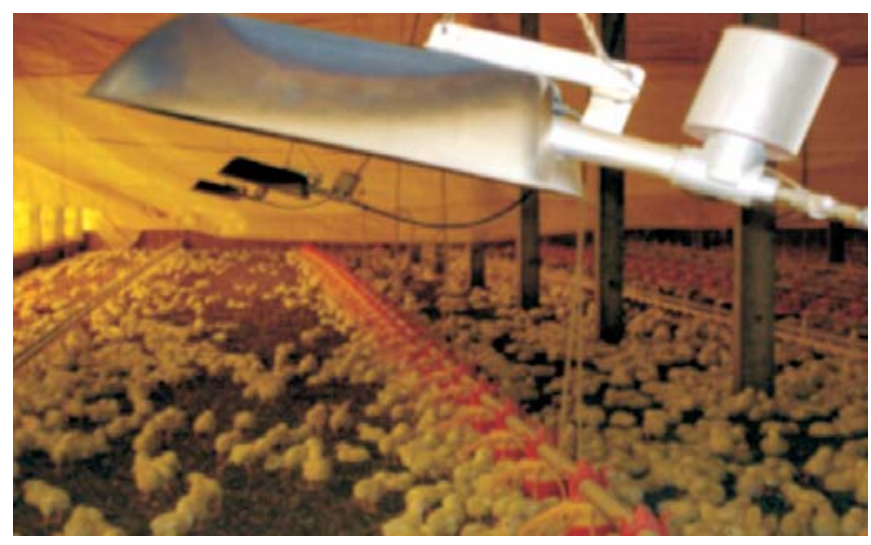

Figura 1. Aviário com sistema de aquecimento automático a lenha (A) e Aviário com sistema de aquecimento automático infravermelho a gás (B)

O sistema de aquecimento automático infravermelho a gás se compõe de 14 campânulas (Figura 1) de forma retangular, com queimador e filtro cilíndrico em aço inoxidável, válvula de segurança, que impede a passagem do gás no caso da chama da campânula se apagar, um sensor de temperatura, que aumenta ou diminui a chama da campânula, conforme 
aumenta ou diminui a temperatura no interior do aviário, um painel de controle em que se regula a pressão do gás e a temperatura desejada, com bateria para o caso de ocorrer falta de energia elétrica, tubulações metálicas para condução do gás ao longo do galpão, mangueiras que ligam os botijões à tubulação e bateria de botijões de gás de 13 kg.

As medidas de consumo de energia elétrica foram tomadas com o auxílio de um medidor/registrador de grandezas elétricas, denominado RE 1000, marca Embrasul. Os valores de tensão e corrente medidos foram utilizados no período de 02/05/2005 a 09/05/2005, e as medições realizadas a cada 15 segundos, em um dos aviários experimentais com sistema de aquecimento automático a lenha e, então, calculado o consumo para todo o lote, com base na capacidade da fornalha, tempo de autonomia informado pelo fabricante e consumo total de lenha.

A medição da quantidade consumida e o custo da lenha e gás foram coletados junto aos produtores de frango dos 36 aviários experimentais, por meio de um questionário. O consumo de lenha foi medido em $\mathrm{m}^{3}$ e o de gás em $\mathrm{kg}$. A temperatura de funcionamento dos dois sistemas de aquecimento foi ajustada nos painéis de controle, de acordo com a idade dos frangos.

Para se obter os resultados de consumo energético e de custos dos sistemas automáticos de aquecimento a lenha e infravermelho a gás, utilizaram-se as equações que seguem; para os cálculos sistema de aquecimento automático a lenha, lançou-se mão das equações a seguir.

\section{1) Para o motor do sistema a lenha}

A potência do motor $(\mathrm{P})$ em $\mathrm{kW}$ foi obtida pela Eq. 1:

$$
\mathrm{P}=\frac{\mathrm{V} . \mathrm{I}}{1000}
$$

em que: V - tensão; I - corrente.

$\mathrm{O}$ consumo energético do motor ( $\left.\mathrm{CE}_{\text {motor }}\right)$ em GJ por lote foi obtido pela Eq. 2:

$$
\mathrm{CE}_{\text {motor }}=\frac{\mathrm{n}^{\mathrm{o}} \text { de horas ligado } \times \mathrm{P} \times 3600 \mathrm{~s}}{1.000 .000}
$$

$\mathrm{O}$ custo da energia elétrica do motor $\left(\mathrm{Ct}_{\text {motor }}\right)$ em $\mathrm{R} \$$ por lote foi obtido pela Eq. 3:

$$
\mathrm{Ct}_{\text {motor }}=\mathrm{P} \times \mathrm{n}^{\mathrm{o}} \text { de horas ligado } \times \text { custo do } \mathrm{kWh}
$$

\section{2) Para o sistema a lenha}

O consumo energético do sistema automático de aquecimento a lenha ( $\mathrm{CE}_{\text {lenha }}$ ) em $\mathrm{GJ}$ por lote foi obtido pela Eq. 4:

$$
\mathrm{CE}_{\text {lenha }}=\frac{\mathrm{CTL} \times \mathrm{PCI} \times \text { mas. espec. }}{1.000 .000}
$$

em que: Consumo energético do sist. a lenha - consumo energético do sistema a lenha; CTL - consumo total de lenha; PCI - poder calorífico inferior da lenha; mas.espec. - massa específica da lenha.
O consumo energético total do sistema automático de aquecimento a lenha $\left(\mathrm{CT}_{\text {lenha }}\right)$ é dado pela Eq. 5:

$$
\mathrm{CT}_{\text {lenha }}=\mathrm{CE}_{\text {motor }}+\mathrm{CE}_{\text {lenha }}
$$

O custo da lenha $\left(\mathrm{Ct}_{\text {lenha }}\right)$ em $\mathrm{R} \$ \mathrm{GJ}$ por lote foi obtido pela Eq. 6:

$$
\mathrm{Ct}_{\text {lenha }}=\frac{\text { Custo } \mathrm{m}^{3} \text { lenha } \times \mathrm{CTL}}{\text { CETSAAL }}
$$

em que: CTL - consumo total de lenha; CETSAAL - consumo energético total do sistema automático de aquecimento a lenha.

\section{3) Para o sistema a infravermelho a gás}

O consumo energético do sistema automático de aquecimento infravermelho a gás ( $\mathrm{CE}_{\text {gás}}$ ) em GJ por lote foi obtido pela Eq. 7:

$$
\mathrm{CE}_{\text {gas }}=\frac{\mathrm{CTG} \times \text { poder calorífico do gás }}{1.000 .000}
$$

em que: Consumo energ.do sist. a gás - consumo energético do sistema a gás; CTG - consumo total do gás; PC - poder calorífico do gás.

O custo do gás ( $\left.\mathrm{Ct}_{\text {gás }}\right)$ em R\$ GJ por lote foi obtido pela Eq. 8:

$$
\mathrm{Ct}_{\text {gas }}=\frac{\text { Custo kg gás } \times \mathrm{CTG}}{\text { CESAAIG }}
$$

em que: CESAAIG - consumo energético do sistema automático de aquecimento infravermelho a gás; CTG - consumo total do gás.

Obtiveram-se, para cada lote de produção, as seguintes variáveis produtivas, conforme Miragliota (2000): mortalidade, conversão alimentar, peso médio e consumo médio de ração.

A mortalidade em cada um dos tratamentos foi obtida pela Eq. 9, usual do manejo da avicultura:

$$
\% \text { Mortalidade }=\frac{\mathrm{n}^{\mathrm{o}} \text { de aves mortas }}{\mathrm{n}^{\mathrm{o}} \text { de pintos de } 1 \text { dia iniciados }} \times 100
$$

A conversão alimentar (CA) ao final de cada lote de produção foi obtida pela Eq. 10:

$$
\mathrm{CA}=\frac{\text { Total de kg de ração consumida }}{\text { total de } \mathrm{kg} \text { de frangos vivos }}
$$

A pesagem das aves foi realizada no dia do abate, em balança eletrônica aferida pelo Instituto Nacional de Metrologia Normalização e Qualidade Industrial - INMETRO, pertencente à agroindústria avícola. O peso médio (PM) das aves foi obtido pela Eq. 11:

$$
\mathrm{PM}=\frac{\text { Total de } \mathrm{kg} \text { de peso de frangos vivos }}{\mathrm{n}^{\mathrm{o}} \text { total de frangos vivos }}
$$


Toda ração enviada para os aviários foi pesada em balança eletrônica da agroindústria avícola. O consumo médio de ração (CMR) das aves foi obtido pela Eq. 12:

$$
\mathrm{CMR}=\frac{\text { Total de } \mathrm{kg} \text { de ração consumida }}{\mathrm{N}^{\mathrm{o}} \text { total de frangos vivos }}
$$

O delineamento experimental foi inteiramente casualizado em um modelo fatorial 2 x 3, dois sistemas de aquecimento (sistema de aquecimento automático infravermelho a gás e sistema de aquecimento automático a lenha), três linhagens ou marcas (Ross 1, Ross 2, Cobb) e sexo macho, composto de seis tratamentos e seis repetições, perfazendo o total de 36 aviários, com 13.300 aves cada um.

As variáveis estudadas foram analisadas utilizando-se o programa de análises estatísticas SISVAR 4.6 (2000), desenvolvido pela Universidade Federal de Lavras - UFLA. As características que apresentaram efeitos significativos tiveram suas médias obtidas pelo teste Tukey.

\section{RESULTADOS E DISCUSSÃO}

\section{Consumo energético do sistema de aquecimento automático a lenha e automático infravermelho a gás}

Os resultados dos consumos energéticos e os respectivos custos se encontram na Tabela 1. No consumo energético do sistema de aquecimento automático a lenha, leva se em conta também o consumo do motor elétrico, que tem a função de acionar a turbina.

Em relação ao consumo energético, nota-se que o maior

Tabela 1. Consumo energético do motor, da lenha e do gás; custo da energia elétrica, da lenha e do gás liquefeito de petróleo (GLP) por lote

\begin{tabular}{|c|c|}
\hline Discriminação & Valor \\
\hline \multicolumn{2}{|c|}{ Motor } \\
\hline Consumo total lenha $\left(\mathrm{m}^{3}\right)$ & 20,00 \\
\hline Tensão (V) & 125,06 \\
\hline Corrente $(A)$ & 8,12 \\
\hline Potência (kW) & 1,015 \\
\hline $\mathrm{N}^{0}$ horas & 111,1 \\
\hline Consumo energético (GJ lote-1) & 0,406 \\
\hline Custo energia elétrica (R\$ kW h-1) & 0,185 \\
\hline Custo energia elétrica ( $\mathrm{R} \$$ lote $\left.^{-1}\right)$ & 20,86 \\
\hline \multicolumn{2}{|c|}{ Lenha } \\
\hline Consumo total - lenha $\left(\mathrm{m}^{3}\right)$ & 20,00 \\
\hline Poder calorífico inferior - lenha $\left(\mathrm{kJ} \mathrm{kg}^{-1}\right)$ & 19.200 \\
\hline Massa específica da lenha $\left(\mathrm{kg} \mathrm{m}^{-3}\right)$ & 450,0 \\
\hline Consumo energético (GJ lote-1) & 172,8 \\
\hline Consumo energético total (GJ lote ${ }^{-1}$ ) & 173,21 \\
\hline Custo $\mathrm{m}^{3}$ da lenha $\left(\mathrm{R} \$ \mathrm{~m}^{-3}\right)$ & 28,00 \\
\hline Custo da lenha (R\$GJ lote ${ }^{-1}$ ) & 3,23 \\
\hline \multicolumn{2}{|c|}{ Gás liquefeito de petróleo (GLP) } \\
\hline Consumo total - gás $(\mathrm{kg})$ & 429,00 \\
\hline Poder calorífico - gás (kJ kg-1) & 47.234 \\
\hline Consumo energético (GJ lote-1) & 20,26 \\
\hline Custo kg do gás ( $\mathrm{RS} \mathrm{kg-1}$ ) & 2,54 \\
\hline Custo do gás (RS GJ lote-1) & 53,78 \\
\hline
\end{tabular}

consumo ocorreu no sistema de aquecimento automático a lenha, com 173,21 GJ lote ${ }^{-1}$, contra 20,26 GJ lote ${ }^{-1}$ do sistema de aquecimento automático infravermelho a gás, possivelmente, devido ao menor poder calorífico da lenha, que é de $19200 \mathrm{KJ} \mathrm{kg}^{-1}$ em relação ao poder calorífico gás liquefeito de petróleo, de $47234 \mathrm{KJ} \mathrm{kg}^{-1}$ (GLP).

O sistema de aquecimento automático infravermelho a gás apontou maior custo com R \$ GJ lote ${ }^{-1} 53,78$, em relação ao sistema de aquecimento automático a lenha cujo custo foi de R\$ GJ lote ${ }^{-1} 3,23$, conforme os dados apresentados na Tabela 1; entretanto, o importante é dispor de capacidade de produção calorífica adequada e com baixo custo, pois esses componentes merecem atenção duplicada, especialmente no inverno, uma vez que o aquecimento é fundamental no início da vida das aves e depende dele o seu bom desenvolvimento.

Para comparação com alguns aquecedores que apresentam efeitos similares, Cardoso Sobrinho et al. (2001) observaram, analisando três sistemas de aquecimento em pinteiros até 14 dias de idade, que o consumo de energia $(\mathrm{kJ})$ apresentou resultados próximos para os sistemas de aquecimento a gás liquefeito de petróleo, a gás natural e energia elétrica.

Analisando sete sistemas de aquecimento, Abreu et al. (2000) verificaram que os tratamentos campânulas a gás e placa de argamassa armada sem cobertura de lona plástica, indicaram o maior consumo de energia em reais, constatando-se menor consumo para o tratamento placa de fibra de vidro com cobertura de lona plástica e, também, que a placa de argamassa armada com cobertura de lona plástica apresentou a maior margem bruta, tanto em reais quanto em dólar e a campânula a gás, a menor margem.

Na experiência da agroindústria avícola, na qual foi realizado o experimento, o sistema de aquecimento automático a lenha é o mais indicado como fonte de calor, haja vista proporcionar boas condições térmicas na criação dos frangos de corte, além de permitir um custo menor com o aquecimento. O uso de lenha possibilita a substituição de outros combustíveis não renováveis e extremamente agressivos ao meio ambiente, como carvão mineral e o petróleo (Farias, 2002), além do mais, uma grande parte da lenha utilizada pelos integrados da agroindústria para aquecimento das aves provém de reflorestamentos, plantados na própria propriedade, solução que promove o desenvolvimento sustentável.

O sistema de aquecimento automático infravermelho a gás, apesar do custo mais elevado, continua sendo utilizado por alguns integrados, em razão de não ser necessário o reabastecimento manual durante a noite.

A utilização de lenha de reflorestamento como combustível, é uma prática correta, uma vez que garante o equilíbrio climático, maior controle da erosão e a sustentabilidade do meio ambiente, devido à menor pressão sobre os remanescentes florestais nativos; ao mesmo tempo, o cultivo florestal possibilita a melhoria da qualidade de vida das pessoas que vivem na zona rural, pois o plantio pode ser feito em terras não aptas para a agricultura, porém a queima incompleta da lenha em fogões precários leva a emissões atmosféricas, compostos aromáticos e fuligem, causando impactos ambientais significativos (Oanh et al., 2005). 
O gás liquefeito de petróleo (GLP), conhecido no Brasil como "gás de cozinha" devido à ampla utilização em cocção, é caracterizado por sua grande aplicabilidade como combustível, graças à facilidade de armazenamento e transporte a partir do seu engarrafamento em botijões, cilindros ou tanques (Ultragaz, 2004, apud Morais, 2005); ainda é utilizado no aquecimento dos aviários por permitir maior autonomia do sistema de aquecimento e ainda pela facilidade de armazenamento e transporte.

A produção brasileira de GLP é limitada, não atendendo à demanda e é completada a partir de GLP importado e, em assim sendo, torna-se imprescindível a racionalização do uso desse combustível (Gasbrasil, 2006).

\section{Desempenho zootécnico de frangos de corte}

Os resultados de desempenho de frangos de corte se acham na Tabela 2; ressalta-se que os frangos submetidos ao sistema de aquecimento automático a lenha e ao sistema automático infravermelho a gás, não apresentaram diferenças estatísticas para peso médio, consumo de ração, conversão alimentar e mortalidade, quando alcançaram os 45 dias de idade, porém é oportuno ressaltar que o sistema de aquecimento automático a lenha indicou uma possível melhora no peso médio das aves da linhagem Cobb, proporcionando-lhes $7,8 \%$ mais peso, quando comparada com a linhagem Ross 1 , que recebeu a mesma fonte de aquecimento; esta mesma tendência se repetiu para a conversão alimentar, porém com um índice percentual menor (2,7\%).

Contrariamente, Abreu et al. (2000), trabalhando com pintos da linhagem Ross verificaram que os sete sistemas de aquecimento estudados diferiram significativamente para a característica de conversão alimentar para aves com até 42 dias de idade.

Na avaliação de parâmetros zootécnicos, com quatro linhagens comerciais de frangos de corte aos 47 dias de idade, Flemming et al. (1999) observaram tendência das linhagens Arbor Acres e Hubbard em consumirem maior quantidade de ração por animal; já as linhagens Ross e Cobb mostraram tendência a melhores resultados em relação à conversão alimentar e ao consumo de ração.

Para os resultados encontrados para mortalidade, observou-se tendência das linhagens Ross 1 e Cobb submetidas ao sistema de aquecimento automático a lenha a apresentarem uma mortalidade maior, em relação ao sistema de aquecimento automático infravermelho a gás, embora as diferenças estatísticas não tenham sido significativas $(\mathrm{p}>0,05)$.

Quanto ao fator linhagem, observa-se que as aves da linhagem Cobb apresentaram maior peso médio 6,62 e 5,09\% e maior mortalidade de 1,04 e 1,36\%, significativamente ( $<<0,05)$, quando comparadas com as linhagens Ross 1 e Ross 2 (Tabela 2).

Comparando quatro linhagens de frango de corte de 1 a 49 dias de idade, Mendes (1990) encontrou diferenças estatísticas no ganho de peso e avaliou as linhagens Hubbard e Arbor Acres aos 48 e 53 dias de idade, encontrando melhor conversão alimentar e menor consumo de alimento para a linhagem Arbor Acres.
Tabela 2. Desempenho de três linhagens de frangos de corte ${ }^{1}$ submetidos a dois sistemas de aquecimento sobre o peso médio (PM), conversão alimentar (CA), consumo médio de ração (CR) e mortalidade (MT)

\begin{tabular}{lcccc}
\hline Tratamento & PM (g) & CA (g g $\left.\mathbf{~}^{-1}\right)$ & CMR (g) & MT (\%) \\
Aquecimento & 2683 & 1,837 & 4925 & 4,61 \\
Linhagem & 2685 & 1,831 & 4916 & 4,66 \\
A gás + Ross 1 & $2632 \mathrm{a}$ & $1,856 \mathrm{a}$ & $4884 \mathrm{a}$ & $4,08 \mathrm{a}$ \\
À gás + Ross 2 & $2672 \mathrm{a}$ & $1,853 \mathrm{a}$ & $4945 \mathrm{a}$ & $4,27 \mathrm{a}$ \\
A gás + Cobb & $2760 \mathrm{a}$ & $1,807 \mathrm{a}$ & $4987 \mathrm{a}$ & $5,34 \mathrm{a}$ \\
A lenha + Ross 1 & $2598 \mathrm{a}$ & $1,850 \mathrm{a}$ & $4805 \mathrm{a}$ & $4,58 \mathrm{a}$ \\
A lenha + Ross 2 & $2635 \mathrm{a}$ & $1,855 \mathrm{a}$ & $4884 \mathrm{a}$ & $3,92 \mathrm{a}$ \\
A lenha + Cobb & $2800 \mathrm{a}$ & $1,801 \mathrm{a}$ & $5043 \mathrm{a}$ & $5,44 \mathrm{a}$ \\
Linhagem Ross 1 & $2615 \mathrm{~b}$ & $1,852 \mathrm{a}$ & $4844 \mathrm{a}$ & $4,33 \mathrm{a}$ \\
Linhagem Ross 2 & $2653 \mathrm{~b}$ & $1,854 \mathrm{a}$ & $4913 \mathrm{a}$ & $4,01 \mathrm{a}$ \\
Linhagem Cobb & $2788 \mathrm{a}$ & $1,790 \mathrm{a}$ & $4991 \mathrm{a}$ & $5,37 \mathrm{~b}$ \\
Erro Padrão da Média & 28,544 & 0,020 & 61,049 & 0,284 \\
CV & 3,63 & 3,78 & 4,24 & 21,18 \\
\hline & Probabilidade Estatística Pr $>\mathrm{F}$ & \\
Aquecimento & 0,770 & 0,900 & 0,629 & 0,829 \\
Linhagem & 0,001 & 0,212 & 0,379 & 0,022 \\
Aquecimento*Ross 1 & 0,497 & 0,799 & 0,668 & 0,240 \\
Aquecimento*Ross 2 & 0,821 & 0,346 & 0,202 & 0,829 \\
Aquecimento*Cobb & 0,670 & 0,422 & 0,451 & 0,791 \\
\hline
\end{tabular}

Nota: Os valores são das médias obtidas das 6 repetições e 79.800 aves por Tratamento. Dentro de cada coluna, médias seguidas de letras diferentes são significativamente diferentes $(p<0,05)$, pelo teste de Tukey

${ }^{1}$ Realizado com frangos de corte machos aos 45 dias de idade

Nesse estudo dos dois sistemas de aquecimento para frangos de corte, cada um apresentou vantagens e desvantagens, no que diz respeito a consumo energético, custo e manejo e também no desempenho das três linhagens comerciais de frangos de corte, em relação ao peso médio, mortalidade, conversão alimentar e consumo de ração; contudo, e devido à escassa pesquisa existente acerca das fontes de aquecimento e do aquecimento sobre o desempenho das diversas linhagens ou marcas de aves macho e fêmea de corte industrial, sugere-se que novos estudos sejam realizados comparando-se os sistemas de aquecimento a gás e a lenha sobre as linhagens, os dois sexos e se analisando o rendimento de carcaça dos frangos de corte.

Quanto ao estudo de sistemas de aquecimento para aviários, é conveniente que se desenvolvam pesquisas com o biodiesel e/ou HBio, biogás como combustíveis alternativos aos tradicionais, para se diversificar as fontes de energia e aumentar as possibilidades de diminuição os custos de um empreendimento avícola.

\section{CONCLUSÕES}

1. O consumo energético foi maior no sistema de aquecimento automático a lenha, mas apresentou menor custo.

2. Os sistemas de aquecimento automático a lenha e o de aquecimento automático infravermelho a gás, não influenciaram significativamente no peso médio, mortalidade, conversão alimentar e consumo de ração.

3. A linhagem Cobb apresentou maior peso e mortalidade em relação às linhagens Ross 1 e Ross 2. 


\section{LITERATURA CITADA}

Abreu, P. G. Diagnóstico bioclimático: qual sua importância na produção de aves. Avicultura Industrial, Porto Feliz, n.1093, p.16-20, 2001.

Abreu, P. G.; Abreu, V. M. N. Caracterização dos sistemas de aquecimento para aves. Concórdia: Embrapa-CNPSA, 2002. 10p. Artigo Técnico 21

Abreu, P. G.; Abreu, V. M. N. Conforto térmico das aves. Concórdia: Embrapa-CNPSA, 2004. 5p. Comunicado Técnico 365

Abreu, P. G.; Abreu, V. M. N.; Perdomo, C. C.; Baeta, F. C. Sistemas de aquecimento para criação de aves. Concórdia: Embrapa-CNPSA, 1998. 35p. Circular Técnica 20

Abreu, P. G.; Baeta, F. C.; Abreu V. M. N.; Soares, P. R.; Perdomo, C. C.; Silva M. A. Desempenho produtivo e bioeconômico de frangos de corte criados em diferentes sistemas de aquecimento. Revista Brasileira de Zootecnia, Viçosa, v.1, n.29, p.159 167, 2000.

Baião, N. C. Efeitos da densidade populacional sobre o ambiente das instalações avícolas. In: Simpósio Internacional sobre Ambiência e Instalação na Avicultura Industrial, 1995. Campinas. Anais... Campinas: FACTA, 1995 p.67.

Cardoso Sobrinho, J.; Barreto M. C. V.; Machado, D. B.; Oliveira, T. M. Uso do gás natural como fonte de energia no aquecimento do ar visando conforto térmico em pinteiro In: Seminário de Pesquisa FAP-SE, 2001. Aracaju. Anais... Aracaju: FAP-SE, 2001. p.2-3.

Conto, L. A. Novos sistemas de aquecimento inicial de pintos de corte. In: Conferência Apinco de Ciência e Tecnologia Avícolas, 2003. Campinas. Anais... Campinas: FACTA, 2003. p.132-136.

Czarick, M.; Lacy, M. P. Getting chicks off to a good start. Poultry housing tips. Cooperative Extension Service, College of Agricultural and Environmental Science, University of Georgia, Athens, v.8, n.10, p.1-3, 1996.

Farias, J. A. C. Manual de reflorestamento da Budny. Florianópolis: Budny, 2002. 20p.

Flemmnig, J. S.; Janzen, S. A.; Endo, M. A. Teste com linhagens comerciais de frango de corte: avaliação dos parâmetros zootécnicos. Archives of Veternary Science, Curitiba, n.4, v.1, p.57-59, 1999.
Gasbrasil. Gás liquefeito de petróleo. http://www.gasbrasil.com.br/ mercadoglp. 13 Mai 2006.

Macari, M.; Furlan, R. L.; Gonzales, E. Fisiologia aviária aplicada a frangos de corte. Jaboticabal: FUNEP, 1994. 296p.

Marques, D. Desempenho de diferentes equipamentos. In: Conferência Apinco de Ciência e Tecnologia Avícolas. Manejo de frangos, 1994. Campinas. Anais... Campinas, FACTA, 1994. p.59-70.

Mendes, A. A. Efeitos de fatores genéticos, nutricionais e de ambiente sobre o rendimento de carcaça de frangos de corte. Botucatu: UNESP, 1990. 103p. Tese Doutorado

Miragliota, M. Y. Avaliação dos níveis de amônia em dois sistemas de produção de frangos de corte com ventilação e densidade diferenciadas. Campinas: UNICAMP, 2000. 122p. Dissertação Mestrado

Morais, A. B. Perspectivas de inserção do GLP na matriz energética brasileira. Rio de Janeiro: UFRJ, 2005. 122p. Dissertação Mestrado

Moro, D. Sistemas de aquecimento em instalações avícolas na fase inicial. In: Simpósio Internacional sobre Ambiência e Instalação na Avicultura Industrial, 1995, Campinas. Anais... Campinas: APINCO, 1995. p.139-144.

Muller, P. B. Bioclimatologia aplicada aos animais domésticos. 3.ed. Porto Alegre: Livraria Editora Sulina, 1989. 158p.

Oanh, N. T. K., Albina, D. O., Ping, L., Wang X. Emission of particulate matter and polycyclic aromatic hydrocarbons from select cookstove-fuel systems in Asia. Biomass and Bioenergy, Oxford, Inglaterra, v.28, p.579 590. 2005.

Silva, R. G. Introdução à bioclimatologia animal. São Paulo: Nobel, 2000. 288p.

SISVAR. Versão 4.6, Lavras: UFLA, 2005. <http:// www.vht.ufla.br>. 05 Ago. 2005

Veste, L. R. Environmental factors to consider when brooding chicks. Athens Cooperative Extension Service, College of Agricultural and Environmental Science, University of Georgia, 1997. Bulletin, 855

Yahav, S.; Luger, D.; Cahaner, A.; Dotan, M.; Rusal, M.; Hurwitz, S. Thermoregulation in naked neck chickens subjected to different ambient temperatures. British Poultry Science, v.39, p.133-138, 1998. 